\title{
Chapter 5 \\ A Resilience Framework for Climate Adaptation: The Shyamnagar Experience
}

\author{
Raquibul Amin and Md Rumi Shammin
}

\section{Key Messages}

- Scenario analysis for resilience building delivers community-led, locally relevant programme development and nature-based solutions.

- Concentration of multiple integrated interventions at the community level produces effective and efficient outcomes.

- Inclusive and collaborative community engagement produces a shared vision for pathways towards a sustainable future.

\subsection{The Old Guard}

But here, in the tide country, transformation is the rule of life: rivers stray from week to week, and islands are made and unmade in days. In other places, forests take centuries, even millennia, to regenerate, but mangroves can recolonize a denuded island in ten to fifteen years. Could it be the very rhythms of the earth were quickened here so that they unfolded at an accelerated pace?-Amitav Ghosh

Disclaimer: The presentation of material and details in maps used in this book does not imply the expression of any opinion whatsoever on the part of the Publisher or Author concerning the legal status of any country, area or territory or of its authorities, or concerning the delimitation of its borders. The depiction and use of boundaries, geographic names and related data shown on maps and included in lists, tables, documents, and databases in this book are not warranted to be errorfree nor do they necessarily imply official endorsement or acceptance by the Publisher, Editor(s), or Author(s).

\footnotetext{
R. Amin Bangladesh e-mail: Raquibul.amin@iucn.org

M. R. Shammin ( $\varangle)$

Environmental Studies Program, Oberlin College, Oberlin, OH, USA

e-mail: rumi.shammin@oberlin.edu
}

Bangladesh Country Office, International Union for Conservation of Nature (IUCN), Dhaka, 
In his tantalizing novel The Hungry Tide, award-winning writer Amitav Ghosh depicted the social and political struggles of the unique social-ecological setting of the Indian Sundarban near Kolkata (Ghosh, 2005). Nature's influence in shaping the past, present and future of the Sundarban area where land meets the sea was brought alive through his narrative. The Sundarban, a World Heritage Site, is the largest contiguous mangrove forest in the world spanning across the border between Bangladesh and India and home of the majestic Bengal tiger-a globally endangered species as per the Red List (IUCN, n.d.). Port Canning, a port city inaugurated in 1864 on the fringes of the Sundarban in South 24 Parganas district in the province of formerly undivided Bengal, was built on the banks of the Matla River but washed away by consecutive cyclones within a few years (Ghosh, 2016). The power the natural world has over land and people in this part of the world is simply overwhelming.

Shyamnagar, a small upazila (sub-district) in Bangladesh, not very far from Port Canning, represents a similar narrative of people's lives shaped by the tides of Kholpetuya and Arpangasia rivers. The oscillating rise and fall in prosperity in Shyamnagar is shaped by the social, economic and political landscape of the region, but more importantly by the tropical cyclones emerging from the Bay of Bengal. Unlike Port Canning, Shyamnagar sits behind the Sundarban which tames the fury of the cyclones to a large extent by the time they arrive here. Lives are still lost, and rice fields, shrimp ghers (ponds) and houses ravaged, but the damage could be a lot more without the natural protection of the Sundarban - the old guard shielding Shyamnagar from the spinning skies and the hungry tides of the Bay of Bengal for centuries.

Cyclone Amphan, which made landfall in May 2020, headed towards Port Canning and Kolkata with similar ferocity as in 1864 and 1867-this time narrowly missing Shyamnagar in its direct path. The area, however, has not always been so lucky. Cyclone Sidr in 2007 and Aila in 2009 left lives and livelihoods in disarray in their wake. When the International Union for Conservation of Nature (IUCN) decided to implement the Mangroves for the Future (MFF) initiative in 2014 with the goal of building resilience in vulnerable communities, Shyamnagar was still suffering from the aftermath of these disasters. This chapter tells the story of the MFF initiative in Shyamnagar and how it applied a resilience framework that deviated from the typical linear project development and implementation models by adopting an approach based on integrating the existing dynamics of the complex social and ecological systems. Lessons learned from this example can inform the development of climate resilient community-based adaptation initiatives and nature-based solutions in other vulnerable communities in South Asia and elsewhere in the world.

\subsection{Shyamnagar: Life on the Edge}

Shyamnagar upazila is located in south-western Bangladesh, near the border between Bangladesh and India (as shown in Fig. 5.1), with a population of more than 300,000 


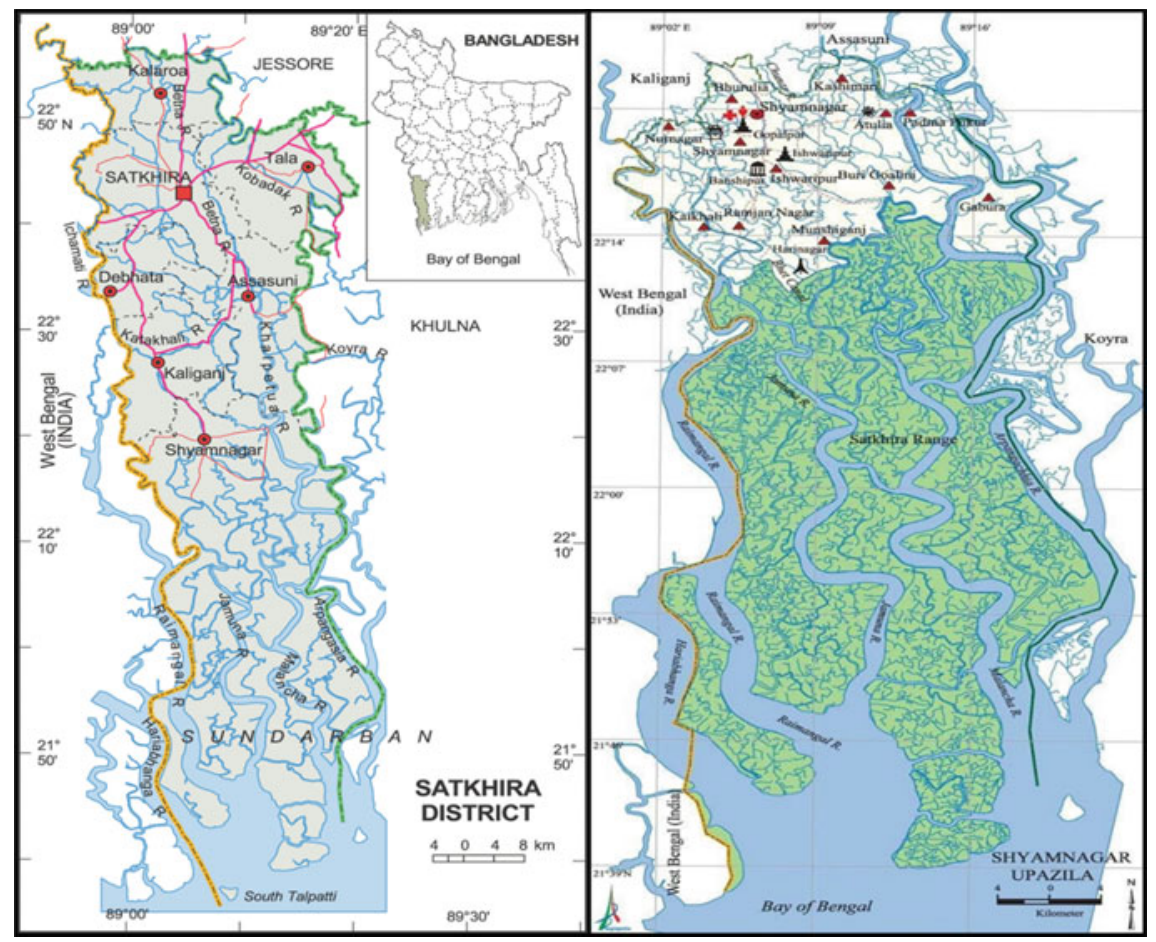

Fig. 5.1 Map of Shyamnagar upazila in the Satkhira district of south-western Bangladesh. Source Banglapedia (n.d.)

inhabiting an area of about $2000 \mathrm{~km}^{2}$ (Bangladesh Bureau of Statistics, 2012). Large parts of the upazila comprise of rivers, canals, agriculture lands and shrimp ghers. This limits the areas available for human settlement, and the communities are concentrated in densely populated enclaves. The area is highly vulnerable to natural hazards such as cyclones and storm surges - compounded by drainage congestion due to the construction of massive polders (circular embankments protecting a land areas) and expansion of saline zones due to increasing shrimp cultivation (IUCN, 2013a).

Shyamnagar lies in a $10 \mathrm{~km}$ wide buffer area beyond the Sundarban Reserve Forest (SRF) boundary that is designated as the Ecologically Critical Area (ECA) ${ }^{1}$ of the SRF. A significant part of the population depends on the Sundarban for its livelihood. For these people, survival is an everyday battle. The declining health of the mangrove ecosystem on the edges of the forest forces them to travel deeper inside the forest to harvest subsistence and economic resources such as honey, crab and other non-timber forest products. Along with storm surges, salinity intrusion and more intense cyclones, this results in further degradation of the ecosystem of the forest. When people venture deeper into the forest, they also face the threat of

\footnotetext{
${ }^{1}$ Ecologically defined areas or ecosystems affected adversely by the changes brought through human activities designated under Bangladesh Environment Conservation (Amendment) Act 2010.
} 
being attacked by the Bengal tiger. A falling population growth rate from $1.7 \%$ in 2001 to only $0.14 \%$ in 2011 (BBS, 2012) highlights the precarious balance of the social and ecological systems that exists in Shyamnagar and indicates the possibility of increasing climate-induced displacement.

With prevailing poverty, proximity to the Sundarban, complexity of the socioeconomic and ecological systems and changing demography with seasonal and permanent outmigration, Shyamnagar presented a challenging environment and creative opportunity for developing and testing a resilience-based approach to climate change adaptation. This required a clear understanding of how the dynamics between coastal ecosystems and human communities has evolved over time and factors that may shape their co-existence in the future. This prompted IUCN to develop a new diagnostic tool to distil local knowledge on human-environment interactions and the issues that impact the tipping points. The centrepiece of this approach was a concerted attempt to create the solutions with the local community to engender local ownership of the resilience building process.

\subsection{RAP: A Systems Approach to Community Resilience}

One of the cornerstones of the MFF initiative was a grant programme with the explicit goal of developing solutions grounded in the realities and needs of the local communities. The programme sought to implement projects with an area-based approach that would identify and incorporate the differing yet connected and interacting perspectives that drive the dynamics of complex social-ecological systems (SES). Systematic evaluation to stimulate a cycle of learning, improvements and generate policy-relevant lessons was also incorporated. One overarching goal was to address the two core questions in the process of resilience building posed by Walker et al. (2002): 'resilience of what?' and 'resilience to what?'. In order to achieve these goals, IUCN developed the Resilience Analysis Protocol (RAP)—a context-specific tool that could be applied to a wide variety of communities across the 11 countries where MFF was operating. The protocol was inspired by the work of the Stockholm Resilience Centre on resilience thinking. Global Climate Adaptation Partnership (GCAP) also provided technical input in drafting of the RAP.

RAP builds on the Drivers-Pressures-States-Impacts-Responses (DPSIR) framework used by the United Nations (UNEP, 2002). The DPSIR is based on a linear causality between drivers, pressures and impacts; a measurable and desirable state of ecosystems and communities; and accurate predictability of future impacts and responses. RAP, however, considers people and nature as interdependent subsystems within a larger dynamic, non-linear social-ecological system (Walker et al., 2010). This approach is the result of decades of research on resilience science that seeks to understand the co-evolving relationship between people and places. It provides insights for providing better support to communities to enable them to use and manage their resources in a sustainable way and respond to shocks at the local scale while 
Fig. 5.2 Five steps of the resilience analysis protocol. Source IUCN (2013b)

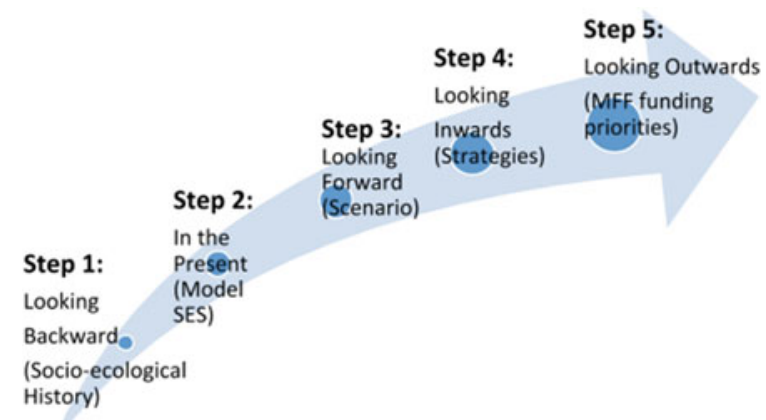

maintaining a broader long-term focus. The RAP consists of five steps illustrated in Fig. 5.2 and described below.

\subsubsection{Step 1: Looking Backward}

This step aims to gather baseline information on the socio-ecological history of the target area and cover issues related to ecosystems and ecological processes; institutional and governance frameworks and actor-network dynamics; characteristics of key drivers of change; and 'disturbances' and pressures including natural hazards and disasters. This process documents a historical narrative using a range of 'tools' or exercises such as unstructured qualitative interviews with individual informants; focused group discussions with stakeholder groups; and application of welldeveloped tools for participatory research such as resource maps, seasonal calendars, historical timelines, institutional Venn diagrams and actor-network mapping.

\subsubsection{Step 2: In the Present}

This step formulates a conceptual model for the coupled social and ecological system for the project site through focused group discussion using the information and knowledge generated in Step 1. The model is preferably represented as a graphic diagram with system boundaries, subsystems, interactions between various subsystems, narrative on the emerging system properties and explanations of the potential impact of unpredictable and uncontrollable drivers (operating at multiple scales) on the system. One of the important issues for developing the conceptual model is determining the possible disturbances that cause disruptions to the system. The disturbances can be episodic/discrete events like cyclones or gradual changes like sedimentation and sea level rise. The timing and magnitude of disturbances can be uncertain like many climate change impacts typically are. They can also be changes 
where causality can be understood by science or direct experience (e.g. land-use change). The other important aspect is to understand the existing governance system and power dynamics among different stakeholder groups. Such analysis is essential to identify the barriers and opportunities for developing and implementing strategies for improving resilience.

\subsubsection{Step 3: Looking Forward}

This step involves scenario building exercises to understand how the unpredictable, exogenous, and uncontrollable drivers might interact with stakeholder behaviour and policy processes to change community access to ecosystem services. Alternative scenarios and future visions are developed to determine the uncertainties associated with drivers, policies and resource management decisions. Stakeholder dialogues involve systematic consideration of a diverse set of information and perspectives to facilitate shared understanding of threats and responses to foster more informed decision-making.

\subsubsection{Step 4: Looking Inwards}

This step focuses on thinking through strategies or factors that might lead to building community resilience. Four filters are used to determine the appropriate contextspecific strategies for implementation:

- Good practice: Tried and tested strategies to cope with predictable changes that would produce measurable results within a couple of years.

- Best practice: Strategies for replication drawn from case studies from elsewhere with similar context.

- Innovative ideas: New or updated place-specific strategies that are likely to lead to enhanced adaptive capacity and local resilience.

- Transformative ideas: Strategies that transform practice into a sustained effort, cross-sectoral solutions and long-term resilience.

Strategies passed through these four filters stand out for two important aspects of resilience: adaptability and transformability. Adaptability refers to the capacity to deal with changes within a regime, and transformability refers to the socialecological capacities that enable shifts from one regime to another (Folke et al., 2010; Olsson et al., 2014; Walker et al., 2002). 


\subsubsection{Step 5: Looking Outwards}

This final step entails leveraging the necessary financial and institutional support for the implementation of the chosen strategies. Funding priorities are documented, possible sources of funding are identified and pursued, and relevant institutional and policy procedures are established.

\subsection{Implementation of RAP in Shyamnagar}

To implement the RAP process in Shyamnagar, considerable time and effort was expended to collect primary and secondary data on the geography, ecology and demographics of the area. This was followed by the establishment of the stakeholder group that would participate in the five steps of the RAP. This group consisting of about 20 people included representatives of community leaders, local government agencies, local NGOs, resource user groups, women and youths. Experience of the RAP facilitators was a key factor in their ability to moderate discussions using the conceptual model. The local social-ecological history, current challenges and future scenarios are summarized based on this participatory process.

\subsubsection{Socio-ecological History}

During the implementation of Steps 1 and 2, four major changes were identified as important parts of the history of Shyamnagar:

- Large-scale ecological and social change: Clearing of the mangroves to reclaim the current settlement area and establishment of the Sundarban Reserve Forest (SRF) in 1876.

- Major hydrological system changes in the aftermath of the Green Revolution: National policy to expand boro rice (a hybrid rice variety) cultivation achieved through the construction of polders or ring dykes that converted the tidal floodplain into stagnant freshwater areas in the 1960s.

- Major shift in the agricultural system and ensuing social conflict: Sharp rise in global demand of shrimp prompted the development of a national policy that supported an exponential growth of shrimp aquaculture in the 1980s. It led to conflict between the freshwater-dependent rice farmers and shrimp farmers as rice farmlands were converted into shrimp aquaculture ponds.

- Climate change, intensifying natural disasters and new stimulants for economic development: Two consecutive cyclones, Sidr in 2007 and Aila in 2009, devastated Shyamnagar, but also brought it into the spotlight in national and international discourses on climate change and disaster risk reduction (DRR). This resulted in considerable external investment into development programmes in the area. 
Shyamnagar became the test site for climate change adaptation and DRR projects for local and international donors and NGOs. Nationwide social and economic changes in terms of gender empowerment, female education and connectivity through mobile communication also penetrated these communities.

These changes triggered a series of social-political transformations in Shyamnagar:

- Embankments and polders built on riverbanks in the late 1960s made the community dependent on the government agency replacing the voluntary community service to build and maintain seasonal bunds/embankments for rice cultivation. The polders slowly weakened over the years till the super cyclones Sidr and Aila washed off major parts of it. An unintended consequence was the siltation of riverbeds due to sedimentation of silt load resulting in drying of rivers and canals and drainage congestion inside the polders.

- The area has traditionally relied on rain-fed agriculture and local varieties of rice. The construction of embankments triggered a shift to commercial agriculture and plantation of hybrid high-yielding varieties of rice. While yield per unit area increased, there was continued loss of agricultural land due to saline intrusionespecially after embankment failures during Sidr and Aila. With the disappearance of traditional rice varieties, farmers have experienced seasonal crop loss and lack of availability of straw and fodder for raising animals in recent years.

- Saline intrusion created a favourable condition for shrimp farming starting in the 1980s and continuing to expand through the 1990s. Many of these shrimp hatcheries were washed away during cyclone Sidr in 2007, following embankment failure. Farmers adapted to grow brackish-white fish. The shrimp farming revived after a while before facing another major shock due to cyclone Aila in 2009. The cycle of boom and bust continues till now. The export-oriented crab farming is getting popular and slowly replacing the shrimp. However, the COVID-19 crisis severely disrupted the supply chain.

- Forest management practices were introduced in the late nineteenth century and continued throughout the twentieth century. Management interventions in Shyamnagar historically followed a revenue-oriented model that propagated embankments, hybrid rice varieties, forest resource management and shrimp cultivation.

- While there were extensive damages to the area forests during Sidr, the forest ecosystem recovered rather quickly. A paradigm shift towards climate change adaptation and community-based disaster risk reduction began in the aftermath of Sidr and Aila.

\subsubsection{Prevailing Challenges}

The dilemma between rice and shrimp cultivation appears to be continuously shaping the fate of Shyamnagar and its people. The linear chain of hazard, vulnerability and 
response is compounded by regional and national policy changes outside Shyamnagar. The large and wealthy landholders have been the main beneficiary of the Green Revolution in the 1960s and were also the first to switch to shrimp cultivation by turning their rice fields into saline aquaculture ponds in the 1980s. They had the required capital and capacity to take risks by investing in a new enterprise. While the polder system was established in the 1960s to protect the rice fields by preventing the entry of saline water into the tidal floodplain, in the 1980s, the large landholders started pumping saline water from rivers to flood the rice field - thereby transforming the landscape with brackish water aquaculture systems.

The small landholders and landless seasonal lease-holder farmers were directly impacted by this shift that had sudden as well as long-term consequences. There were instances where powerful shrimp farmers inundated agricultural land with saline water-quickly transforming the hydrology and ecology of the area. Parallelly, gradual build-up of salinity forced farmers to abandon rice cultivation over time with accompanying loss of livestock and poultry. It also changed the role of women in these communities who used to lead the post-harvest activities of rice farming. Especially after Aila, trees started dying fast and the ponds remained saline. This caused scarcity of drinking water forcing women to travel long distances daily to collect water.

Shrimp postlarvae (PL.) collection and seasonal demands for day labourers in the shrimp farms offered some alternative sources of income. Rice cultivation continued in land was not suitable for shrimp farming. With monsoon rain washing out the soil salinity, a reduced level of rice cultivation is still possible in the area during the wet season. Seasonal outmigration has become a coping strategy for the landless agricultural labourers and small farmers. Another impact has been increased pressure on the Sundarban ecosystem for subsistence and economic resource extraction.

Both rice farmers and shrimp farmers need durable embankments for protection against regular tidal waves and recurring storm surges. However, there is conflict between the groups in terms of the operation of the sluice gates; shrimp cultivators want saline water inside the embankment, whereas farmers want to keep the saline water out. Some sluice gates were illegally constructed, and water pipes were placed through the polders to draw saline water from rivers. It weakened the polders and potentially contributed to their breach by Aila. Even though the government repaired the embankments quickly, people could not make productive use of the affected land for almost two years in many parts of Shyamnagar. Shrimp farmers faced litigation due to the damage they caused to the embankments which were eventually dropped due to strong political lobbying by the shrimp farmers association. However, the litigation triggered a change in practice, at least temporarily. The shrimp farmers agreed to use low-lift pumps to collect saline water from the rivers without incurring any physical damage to the polders.

The embankment was breached again by cyclone Amphan in May 2020. It appears that the same cycle of incidences was repeated leading to the embankment breach. The vulnerability of people and environment of Shyamnagar, thus, is the product of three factors: climate change increasing the frequency and intensity of cyclones and sea level rise; national policy decisions to pursue structural solutions (e.g. polders) and 
propagate hybrid rice varieties and shrimp farming; and the collective or individual actions that undermined the integrity of the embankments. Climate change is going to make some of these decisions and actions worse in the coming years. A thorough understanding of these interconnected endogenous and exogenous drivers is a crucial prerequisite of effective resilience planning.

\subsubsection{Future Opportunities}

During scenario planning, it was interesting to note that people did not mention the word 'climate change' despite the fact that they had been exposed to the concept as part of a number of ongoing climate change-related projects in Shyamnagar. People were more concerned with the immediate problems and issues that they face on a day-to-day basis such as recovery in the aftermath of Aila, the conflict between shrimp cultivation and agriculture, increasing tide height, embankment malfunction, local governance, salinity intrusion and freshwater crisis. However, participants demonstrated good understanding of the cause-and-effect linkages between environmental degradation and human suffering - which is a core concept of complex socio-ecological systems.

Two extreme scenarios set the boundaries of the scenario planning process: an optimistic vision that current trends and issues would reach a tipping point that would trigger a series of integrated planning initiatives fostering a positive growth trajectory for the community;and a pessimistic vision of further worsening of current socioeconomic and ecological degradation leading to collapse. In between the extremes were scenarios with further consolidation of individual wealth and higher investment on natural resource-based enterprises such as shrimp farms and crab farms as well as progressive ideas such as women's empowerment, spread of information and communication technology, building social networks and local capacity building resulting in various social and environmental outcomes.

The Shyamnagar RAP participants ended up choosing a more optimistic future that envisioned Shyamnagar as the agent of change in writing the history of a prosperous future. The community envisaged a community-based disaster risk reduction approach to bounce back quickly after any disaster. An ecosystem protected by embankments and a mangrove forest established through co-management systems that would provide both protection from storm surges and a steady flow of ecosystem services. The community also predicted export of value-added products from Shyamnagar and a steady growth in ecotourism to generate the dual benefit of employment creation and conservation of the Sundarban. New technologies would increase production of rice, shrimp, crab and fish substantially. A community-based local water management system would create integrated water management systems, and a piped water distribution system would end the drinking water crisis and ensure safe drinking water for all. All of these would be supported by a strong local governance system that would transform Shyamnagar into a model community. 
This narrative was very inspiring for the participants to begin to consider actions that need to be taken today and between now and the future to achieve the desired vision. The timeline was arbitrarily set at 2050. The extended time horizon helped participants to plan short, medium and long-term strategies. A total of 24 strategies were proposed which falls under the four key features of general resilience building: learning to live with change and uncertainty; nurturing diversity for reorganization and renewal; combining different types of knowledge for learning; and creating opportunity for self-organization towards social-ecological sustainability (Folke et al, 2003).

\subsection{RAP Outcomes in Shyamnagar}

The RAP process in Shyamnagar generated ideas for a diverse set of strategies ranging from local actions to national policy. These were mapped against the priorities of the MFF grant-which was intended to pilot short- to medium-term strategies, take feedback, and facilitate local actions while pursuing policy advocacy at the national level for issues which cannot be solved through local initiatives. This resulted in the following priorities that intersected the visions of the community with the scope of the MFF grant.

- Livelihoods support for forest-dependent communities, especially targeting women for eco-friendly enterprise development and market linkage

- Freshwater conservation and innovations in freshwater utilization

- Community initiatives for responsible ecotourism

- Community-based climate change adaptation to reduce climate change vulnerabilities

- Better environmental performance of the shrimp ghers and introducing innovations like mangrove shrimp culture

- Community initiatives for participatory mangrove restoration.

The priority issues formed the narrative for a call for proposals published in newspapers for local NGOs to apply for the MFF grants, and 16 grant projects were funded between 2013 and 2017. The stakeholder group that participated in the RAP process formed a strong network of community advocates during the implementation of these projects. They continued to liaise with the local government agencies, local government and the non-governmental organizations (NGOs). Some NGOs which were MFF grantees continued to work on the projects beyond the project timeline. The grant projects, co-designed with the local community and implemented by local NGOs, helped set a new trajectory for the socio-ecological systems in Shyamnagar to move towards a shared vision of an optimistic future. The process augmented local adaptive capacity to manage the uncertainty of living in a dynamic environment.

Restoration of freshwater supplies has made safe drinking water available to 750 families year-round. A total of 133 rainwater harvesting systems have been established. All reservoirs and water systems are managed by community members. More 
than 1200 marginal farmers cultivated their second crop with the water stored in the re-excavated canal and ponds and adopted climate-smart agriculture including alternative crops such as wheat, salt-tolerant rice and sunflower. Alleviation of household water stress has freed up women to explore alternative incomes such as mat weaving and ecotourism. It has also reduced their 'invisible labour' of having to travel long distances in search of potable water. Interventions at the farm and household level have improved household well-being through diversification of agricultural practices and income sources. Families who were involved in various MFF-funded projects formed community groups and engaged in communal entrepreneurship. Nearly, 500 entrepreneurs engaged in 12 enterprises, and their supplementary income increased by $12-15 \%$. Development of a decentralized and representative governance system has resulted in improved local management of resources. About 200 shrimp farmers were trained in organic shrimp cultivation, and they planted mangroves in their shrimp farms. About 100 farmers received organic certification in 2017 (Karim et al., 2019).

Mangrove conservation is a socially and financially attractive approach for building resilience (Das, 2021, Chap. 17 of this volume). Targeted policies to ensure access to external finance for access to natural capital through extensive mangrove forest coverage can improve climate resiliency in coastal communities (Mahmud et al., 2021, chapter 20 of this volume). Under the MFF grant, about 150 ha of mangrove forest have been rehabilitated, and higher fish abundance has been observed in the vicinity of newly planted mangrove forest. The model was replicated by other development partners resulting in the protection of more than 400 ha of mangrove areas. The local government (Union Parishad) works with a 35 -member forest management committee as stewards of the mangroves. The revenue from the forest (fruits, honey and nursery) is distributed between the community (40\%), Union Parishad (40\%) and a fund to cover forest management expenses (20\%). A community-led ecotourism operation has been installed to diversify livelihoods while engaging the community in forest conservation. Local people have been trained to manage the ecotourism programme, and women have been offered culinary lessons. The ecotourism enterprise includes eco-cottages, eco-boats and motorboats and tours for tourists by local guides (MFF, 2018).

\subsection{Lessons from Shyamnagar}

\subsubsection{Scenario Analysis is Useful}

The scenario analysis process implemented in Shyamnagar was found to be a valuable tool for expanding thinking about how unpredictable and uncontrollable endogenous and exogenous drivers interact with stakeholder behaviour and policy processes. Scenarios can typically be developed either for a short timeline (5-10 years) or for much longer ones (20-30 years). For Shyamnagar, stakeholders found looking far into the future to be more appropriate due to the slow onset changes like climate 
change impacts, sea level rise, salinity ingress, ecological changes and social-cultural transformations like women's empowerment, outmigration and digitalization. The longer timeline allowed participants to think beyond the usual short-term 'project' timeframe and develop a shared vision.

\subsubsection{Visioning with the Community is Valuable}

The RAP process engaged a wide range of stakeholders from the local policymakers, local leaders, practitioners, different user groups, women and youths in collaborative visioning and planning. The 'Golden Shyamnagar 2050' vision that resulted from this process reflects the diverse perspectives of this representative group. The process also exposed the historical inequities in the transition from rice farming to shrimp cultivation in the 1980s that favoured the wealthy in the community. If the trends in shrimp cultivation shift towards crab farming in the future, the design and delivery of that transition can be informed by past experiences to develop systems that ensure a fair distribution of benefits in the community. Developing both freshwater and brackish water-based enterprises promises a more robust and resilient solution.

\subsubsection{Program Density Matters}

Karim et al. (2019) conducted a review of MFF projects in Shyamnagar and concluded that the grants positively contributed towards resilience building through increased income, diversification of income sources, improved health, time savings due to less sick days and better access to safe drinking water. The study also found that the programme density or concentration in a community, not the number of interventions, played a more important role in the diversification of income sourcesleading to greater community resilience against climate change. The provision for 16 small and medium sized grants under the MFF facilitated a flexible planning and implementation process that stimulated the development of a set of synergistic and complementary initiatives. This fostered the creation and strengthening of decentralized, multi-dimensional communitynetworks involving broad participation and ownership at the local level (e.g. the community water association).

\subsubsection{Focus on Future Opportunities Fosters Creative Solutions}

An interesting lesson learned from the Shyamnagar example is the departure from discussions framed around climate change-which is more common in vulnerability 
analysis and adaptation project planning. The RAP process allowed people to expand the scope of stakeholder deliberations beyond hazard-specific discussions on problem identification and adherence to known solutions. It helped people to untangle the dynamics of place-based social and ecological issues to create a shared understanding of where and how to intervene in the journey towards a more sustainable future. While doing so, it allowed people to think of strategies or pathways for that journey; what to avoid to keep the system in a desired trajectory; how to empower local people to self-organize; mechanisms to foster greater local ownership and control; and ways to build communities' capacity to manage the future evolution of Shyamnagar.

\subsection{The Way Forward}

Ever since IUCN deployed the RAP, several new tools for resilience planning have emerged. The Stockholm Resilience Centre has developed the seven principles of resilience to guide programme development and implementation in the pursuit of community resilience (Stockholm Resilience Centre, n.d.). A new software platform, Wayfinder, has been developed for executing efficient and systematic community engagement by the Guidance for Resilience in the Anthropocene: Investments for Development programme (GRAID, n.d.) — hosted by the Stockholm Resilience Centre and funded by the Swedish International Development Cooperation Agency (Sida). The lessons learned in Shyamnagar have directly informed the development of these tools. Other tools, such as Nexus Assessment (Brunner et al., 2019), offer a multi-stakeholder engagement simulation on a given scale such as a river basin or watershed. Greater use of these types of tools and processes is likely to mainstream community-based approaches to climate change adaptation and resilience building. This will help establish greater legitimacy of the knowledge, agency and engagement of local people and communities as owners, implementers and shareholders in climate adaptation, natural resource management and community development solutions. Best practices from Shyamnagar fit well with IUCN's current initiatives on nature-based solutions (NBS) which involve 'actions to protect, sustainably use, manage and restore natural or modified ecosystems, which address societal challenges, effectively and adaptively, providing human well-being and biodiversity benefits' (IUCN, 2020). Shammin et al. (2022, Chap. 2 of this volume) offers an integrative framework for building climate-resilient communities that embodies the lessons from Shyamnagar.

The Shyamnagar story demonstrates the value of community-based approaches to resilience building. This is not an idealistic story of a perfect solution; rather, it is the story of using local knowledge and building local capacity to empower communities to navigate through the nuances of socio-economic realities, threats of climate change and the complexities of social-ecological systems. As the skies continue to spin faster and the hungry tides become stronger, programmes like the MFF are helping the community to find resilience through conviction, collective endeavours, human 
ingenuity and conservation of the mangrove forests of the Sundarban - the old guard that is poised to watch over Shyamnagar for centuries to come.

Acknowledgements Partial support for this research was provided by an implementation grant from the Henry Luce Foundation's Luce Initiative on Asian Studies and the Environment (LIASE) for Faculty Research Support at Oberlin College. The authors acknowledge the MFF donorsSwedish International Development Cooperation Agency, Norwegian Agency for Development Cooperation and Danish International Development Agency-as well as the MFF institutional partners and the MFF Secretariat staff.

\section{References}

Bangladesh Bureau of Statistics. (2012). Statistical yearbook of Bangladesh. Ministry of Planning, Government of Bangladesh.

Banglapedia. (n.d.). The national encyclopaedia of Bangladesh. http://en.banglapedia.org/ index.php?title=Shyamnagar_Upazila and http://en.banglapedia.org/index.php?title=Satkhira_ District. Accessed October 18, 2020

Brunner, J., Carew-Reid, J., Glemet, R., McCartney, M., \& Riddell, P. (2019). Measuring, understanding and adapting to nexus trade-offs in the Sekong, Sesan and Srepok Transboundary River Basins (Viii + 70pp). IUCN: VietNam Country Office.

Das, S. (2021). Valuing the role of mangroves in storm damage reduction in coastal areas of Odisha. In A. K. E. Haque, P. Mukhopadhyay, M. Nepal, \& M. R. Shammin (Eds.), Climate change and community resilience: Insights from South Asia. Springer.

Folke, C., Colding, J., \& Berkes, F. (2003). Synthesis: Building resilience and adaptive capacity in social-ecological systems. In F. Berkes, J. Colding, \& C. Folke (Eds.), Navigating socialecological systems: Building resilience for complexity and change (pp. 352-387). Cambridge University Press.

Folke, C., Carpenter, R. R., Walker, B., Scheffer, M., Chapin, T., \& Rockström, J. (2010). Resilience thinking: Integrating resilience, adaptability and transformability. Ecology and Society, 15(4), 20. http://www.ecologyandsociety.org/vol15/iss4/art20/.

Ghosh, A. (2005). The hungry tide. Houghton Mifflin.

Ghosh, A. (2016). The great derangement: Climate change and the unthinkable. The University of Chicago Press.

Guidance for Resilience in the Anthropocene: Investments for Development. (n.d.). Stockholm Resilience Centre and the Swedish International Development Cooperation Agency (Sida). https://graid.earth/projects/wayfinder/. Accessed September 11, 2020

International Union for Conservation of Nature. (n.d.). Red list of threatened species. https://www. iucnredlist.org/species/136899/4348945. Accessed September 11, 2020

International Union for Conservation of Nature. (2013a). Past, present and future of Shyamnagar: Citizen's analysis. Report prepared for the Mangrove for the Future (MFF) initiatives.

International Union for Conservation of Nature. (2013b). Resilience Analysis Protocol (RAP) for MFF project sites: Scoping challenges and setting strategies (unpublished report).

International Union for Conservation of Nature. (2020). Global standard for nature-based solutions. A user-friendly framework for the verification, design and scaling up of $\mathrm{NbS}$ (1st ed.). IUCN.

Karim, S., Ahmed, M. U., \& Tulon, K. M. N. I. (2019). Analyzing the effectiveness of MFF-SGF program on household and community resilience to climate change in Bangladesh. Asian Center for Development.

Mangroves for the Future. (2018). Annual report to the Regional Steering Committee. 
Mahmud, S., Haque, A. K. E., \& De Costa, K. (2021). Climate resiliency and location specific learnings from coastal Bangladesh. In A. K. E. Haque, P. Mukhopadhyay, M. Nepal, \& M. R. Shammin (Eds.), Climate change and community resilience: Insights from South Asia. Springer.

Olsson, P., Galaz, V., \& Boonstra, W. J. (2014). Sustainability transformations: A resilience perspective. Ecology and Society, 19(4), 1.

Shammin, M. R., Haque, A. K. E., \& Faisal, I. M. (2022). A framework for climate resilient community-based adaptation. In A. K. E. Haque, P. Mukhopadhyay, M. Nepal, \& M. R. Shammin (Eds.), Climate change and community resilience: Insights from South Asia. Springer.

Stockholm Resilience Centre. (n.d.). Stockholm University. https://www.stockholmresilience.org/. Accessed September 11, 2020

United Nations Environment Programme. (2002). Global Environment Outlook 3: Past, present and future perspectives. Earthscan.

Walker, B., Carpenter, S., Anderies, J., Abel, N., Cumming, G., Janssen, M., Lebel, L., Norberg, J., Petersen, G. D., \& Pritchard, R. (2002). Resilience management in social-ecological systems: A working hypothesis for a participatory approach. Conservation Ecology, 6(1), 14.

Walker, B., Gunderson, L., Quinlan, A., Kinzig, A., Cundill, G., Beier, C., Crona, B., \&Bodin, Ö. (2010). Assessing resilience in social-ecological systems: Workbook for Practitioners. Version 2. Resilience Alliance.

Open Access This chapter is licensed under the terms of the Creative Commons AttributionNonCommercial-NoDerivatives 4.0 International License (http://creativecommons.org/licenses/bync-nd/4.0/), which permits any noncommercial use, sharing, distribution and reproduction in any medium or format, as long as you give appropriate credit to the original author(s) and the source, provide a link to the Creative Commons licence and indicate if you modified the licensed material. You do not have permission under this licence to share adapted material derived from this chapter or parts of it.

The images or other third party material in this chapter are included in the chapter's Creative Commons licence, unless indicated otherwise in a credit line to the material. If material is not included in the chapter's Creative Commons licence and your intended use is not permitted by statutory regulation or exceeds the permitted use, you will need to obtain permission directly from the copyright holder.

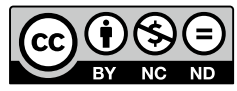

